\title{
Aspectos clínicos e anatomopatológicos de lesões ósseas secundárias a Pythium Insidiosum em equino
}

\author{
Clinical and anatomopathological aspects of bone lesions secondary \\ to Pythium Insidiosum in horses
}

Paula Alessandra Di Filippo (D), Gabriela Bravim Lemos iD*, Marcos Aurélio Dias Meireles, Ítalo dos Santos Coutinho, Francielli Pereira Gobbi iD, Ana Bárbara Freitas Rodrigues Godinho

Universidade Estadual do Norte Fluminense Darcy Ribeiro (UENF), Campos dos Goytacazes, RJ, Brasil

\section{Resumo}

O objetivo deste estudo foi descrever e discutir os sinais clínicos, lesões macro e microscópicas, epidemiologia e métodos de diagnóstico de um caso de pitiose cutânea equina, com envolvimento ósseo e desfecho fatal. Um equino macho Mangalarga Marchador, 6 anos de idade, proveniente da região Norte Fluminense, apresentou ferida ulcerativa granulomatosa de aproximadamente $18 \mathrm{~cm}$ de diâmetro, localizada no terço médio do terceiro metacarpiano esquerdo (ME). Claudicação, edema, prurido, sinais de automutilação, exsudação serossanguinolenta e presença de material caseificado de cor branco-amarelada foram observados. Histopatologicamente foram verificadas reações granulomatosas eosinofílicas e neutrofílicas com

* Autor correspondente: gblemos.vet@gmail.com Submetido: 29 ago 2019 | Aprovado: 16 jan 2020 abundante tecido fibrovascular, associadas à presença de hifas intralesionares. $O$ exame radiográfico revelou extensa e desorganizada proliferação óssea, osteólise do $2^{\circ}, 3^{\circ}$ e $4^{\circ}$ ossos metacarpianos esquerdos e mineralização dos tecidos moles. A biópsia óssea revelou o envolvimento de Pythium insidiosum e o animal foi submetido à eutanásia após insucesso no tratamento. Feridas cutâneas de Pythium insidiosum localizadas nos membros de equinos podem desencadear lesões ósseas. O envolvimento do tecido ósseo favorece a permanência do agente no organismo e constitui um critério para estabelecer prognóstico desfavorável.

Palavras-chave: Pitiose. Osteomielite. Cavalo. 


\section{Abstract}

The aim of this study was to describe and discuss the clinical signs, macro and microscopic lesions, epidemiology and diagnostic methods of a case of equine cutaneous pythiosis, with bone involvement and fatal outcome. A 6-year-old male Mangalarga Marchador horse from the North Fluminense region had a granulomatous ulcerative wound approximately $18 \mathrm{~cm}$ in diameter, located in the middle third of the third left metacarpal (ME). Lameness, oedema, pruritus, signs of self-mutilation, serosanguineous exudation, and presence of yellowish-white caseified material were observed. Histopathologically, eosinophilic and neutrophilic granulomatous reactions were observed with abundant fibrovascular tissue, associated with the presence of intralesional hyphae. Radiographic examination revealed extensive and disorganized bone proliferation, osteolysis of the 2nd, 3rd and 4th left metacarpal bones and soft tissue mineralization. Bone biopsy revealed the involvement of Pythium insidiosum, and the animal was euthanized after treatment failure. Pythium insidiosum skin wounds on equine limbs can trigger off bone lesions. The involvement of bone tissue favors the persistence of the agent in the body, and it is a criterion to establish unfavorable prognosis.

Keywords: Pitiosis. Osteomyelitis. Horse.

\section{Introdução}

A pitiose é uma doença granulomatosa que acomete equinos, caninos, bovinos, ovinos, felinos (Galiza et al., 2014), aves e humanos (Mendoza et al.,1996; Bosco et al., 2005). Ocorre em regiões tropicais, subtropicais ou temperadas e é causada pelo oomiceto Pythium insidiosum, microrganismo aquático que se caracteriza pela formação de zoósporos móveis biflagelados (Mendoza et al.,1996). Produzidos e liberados periodicamente no ambiente aquático, os zoósporos são capazes de colonizar plantas e, em condições especiais, penetrar na pele dos equinos e de outros mamíferos, onde se encistam, iniciando a infecção cutânea (Leal et al., 2001). O acúmulo de água em banhados e lagoas, a presença de vegetação aquática e temperaturas entre 30 e $40{ }^{\circ} \mathrm{C}$ são fatores essenciais que influenciam a ocorrência da doença. Casos clínicos são observados durante todo o ano, mas a maioria coincide com épocas de maior precipitação pluviométrica, não havendo relatos da transmissão direta entre animais ou entre animais e humanos (Mendoza et al.,1996; Gaastra et al., 2010).

No Brasil, especificamente no pantanal brasileiro, onde há a maior incidência da doença, a pitiose é conhecida como "ferida brava" ou "ferida da moda" (Leal et al., 2001). Já no estado do Rio de Janeiro, especificamente na região da Baixada Campista, é denominada "formigueiro" (Carvalho et al., 2000). A enfermidade tem evolução rápida e o sucesso no tratamento é influenciado pelo tamanho, tempo, localização das lesões e, possivelmente, pela idade e estado fisiológico do animal (Mendoza et al.,1996). As lesões se distribuem frequentemente nas extremidades distais dos membros e região tóraco abdominal ventral, embora ocorram também na face (Santurio et al., 2006).

A forma cutânea corresponde à apresentação clínica mais comum da doença, caracterizada por granulomas subcutâneos ulcerados, entrecortados por trajetos fistulosos, preenchidos por material necrótico, amarelado, seco e friável denominado kunkers (Santurio et al., 2006). Acometimento ósseo foi descrito por Alfaro e Mendoza (1990), sendo caracterizado por lesões ulcerativas e granulomatosas extensas, claudicação, edema, automutilação, prurido intenso e alterações radiográficas que indicavam osteomielite. Assim sendo, o objetivo deste trabalho é relatar e discutir os sinais clínicos, os achados radiográficos, as lesões macroscópicas e microscópicas, além das características histológicas e da cultura do agente associadas ao diagnóstico de lesões ósseas secundárias a Pythium insidiosum em um equino, bem como caracterizar os aspectos epidemiológicos que determinaram sua ocorrência na região.

\section{Relato de caso}

Descreve-se o quadro de um equino macho da raça Mangalarga Marchador, com 6 anos de 
idade e $350 \mathrm{~kg}$ de peso corporal, criado em uma propriedade localizada na região Norte Fluminense, o qual apresentou, no membro torácico esquerdo (MTE), ferida de difícil cicatrização com aproximadamente 60 dias de evolução. A lesão apresentou crescimento rápido e progressivo, pruriginosa, refratária a tratamentos com pomadas cicatrizantes, organofosforados, repelentes e ivermectina. Na ocasião da abordagem, verificouse lesão cutânea única, de formato circular, ulcerada, granulomatosa, com diâmetro de $12 \mathrm{~cm}$, na face dorsal do terceiro metacarpiano esquerdo. Apresentava superfície úmida e hemorrágica (Figura 1).

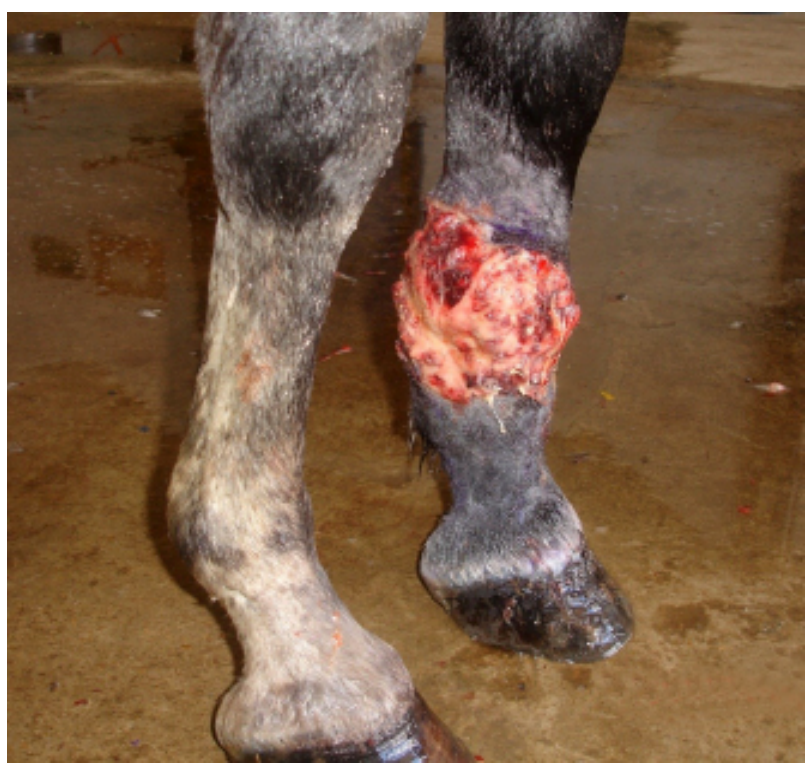

Figura 1 - Pitiose cutânea em região metacárpica esquerda de um equino. Vista medial do terceiro metacarpo do membro torácico esquerdo. Presença de lesão cutânea única, de formato circular, com superfície hemorrágica, ulcerada e granulomatosa.

Focos necróticos eram visibilizados em permeio à lesão e, ao serem explorados por palpação e pressão digital, expeliam pequenas estruturas branco-amareladas, facilmente destacáveis, medindo em torno de um a três milímetros, compatíveis com kunkers. Os sinais vitais se encontravam dentro dos limites fisiológicos para a espécie.
Frente à suspeita clínica de pitiose, procedeuse a exérese cirúrgica do tecido granulomatoso. O procedimento foi realizado com o animal em posição quadrupedal, sob neuroleptoanestesia e anestesia regional intravenosa (Bier). Macroscopicamente, o tecido removido era de coloração esbranquiçada, consistência firme, entrecortado por galerias, as quais continham material necrótico branco-amarelado e que se desprendiam facilmente do tecido circunjacente (kunkers), quase sempre envoltos por exsudato purulento. No exame direto dos kunkers, as massas foram colhidas, trituradas e clarificadas com hidróxido de potássio a $20 \%$, possibilitando a observação de um emaranhado de hifas de paredes finas e hialinas com raras ramificações em ângulo reto. Fragmentos de tecidos removidos foram fixados em solução de formol tamponado neutro a $10 \%$ e processados segundo técnicas histopatológicas de rotina, colorações especiais, PAS e Grocott-Gomori. Foram visibilizadas áreas de necrose contendo imagens negativas tubuliformes de hifas ramificadas e irregulares semelhantes à oomicetos do gênero Pythium. O diagnóstico foi de dermatite piogranulomatosa extensa, associada a "pseudo-hifas" características de Pythium insidiosum (Figuras 2A e 2B).

Instituiu-se tratamento com aplicação de um frasco de imunoterápico Pitium-vac ${ }^{\circledR}$ a cada 14 dias, por via subcutânea (SC), com acompanhamento diário da evolução do caso. Foram aplicadas quatro doses do imunoterápico, além de antibióticos [penicilina benzatina, $30.000 \mathrm{UI}$ $\mathrm{kg}^{-1}$, via intramuscular (IM), a cada 48 horas, perfazendo três aplicações], antiinflamatórios [flunixin meglumine, $0,5 \mathrm{mg} \mathrm{kg}^{-1}$, via intravenosa (IV), duas vezes ao dia por cinco dias] e curativos (iodo povidine tópico 2\%) da ferida cutânea. A cicatrização da ferida ocorreu por segunda intenção e não foram observadas complicações. Entretanto, 45 dias após a alta hospitalar, o animal retornou apresentando linfangite exacerbada do MTE, apatia, emagrecimento acentuado e claudicação. Um pequeno orifício havia surgido na área de cicatrização e ao ser explorado manualmente, estruturas compatíveis com kunkers foram novamente removidas. A secreção presente era serossanguinolenta e fétida. 

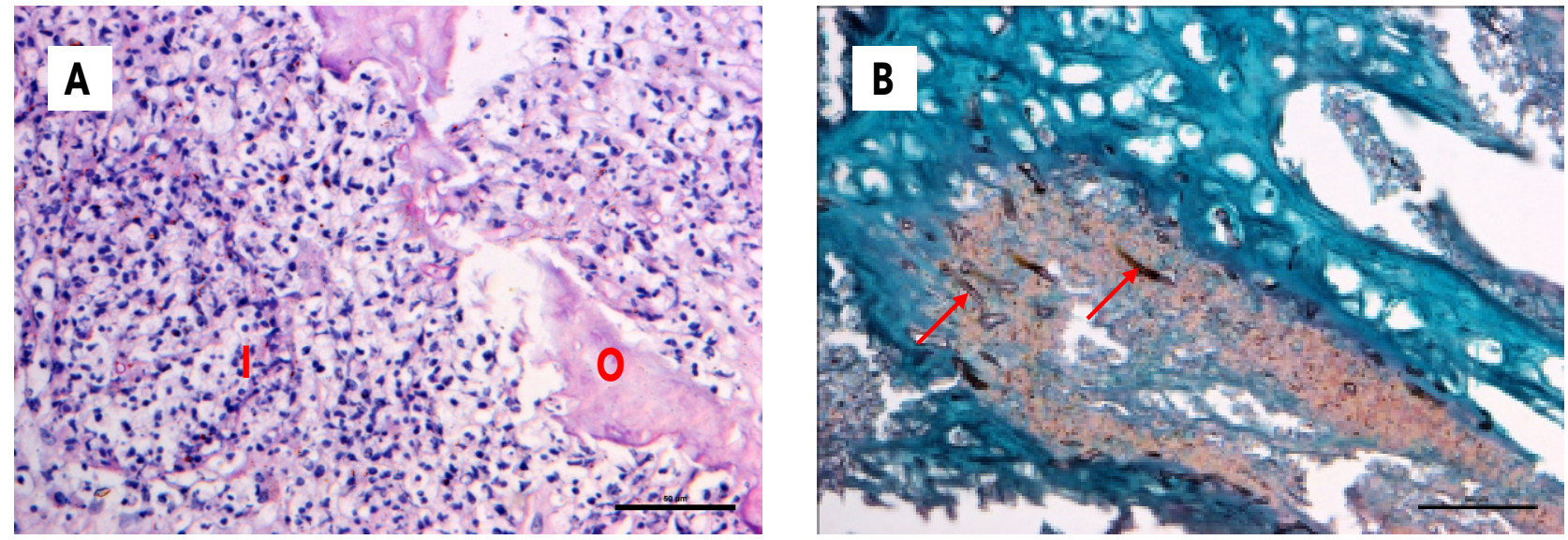

Figura 2 - Fotomicrografia da lesão cutânea de um equino acometido pelo oomiceto Pythium insidiosum. A Proliferação óssea $(\mathrm{O})$ associada à imagem negativa de hifas permeadas em infiltrado inflamatório misto (I). H/E; B - Hifas (setas) sugestivas de Pythium insidiosum entremeadas no infiltrado inflamatório misto presente na lesão; coloração Prata Metenamina de Grocott-Gomori.

O exame radiográfico revelou extensa e desorganizada proliferação óssea (exostose), osteólise do $3^{\circ}$ e $4^{\circ}$ ossos metacarpianos esquerdos e mineralização dos tecidos moles (Figura 3A). O diagnóstico foi de osteomielite e uma biópsia óssea foi realizada. Histopatologicamente, pelo método hematoxilina-eosina (HE), observouse um piogranuloma eosinofílico com inúmeras áreas necróticas de sequestro, células gigantes, linfócitos, neutrófilos e proliferação óssea. $\mathrm{O}$ material semeado em caldo Agar Sabouraud Dextrose resultou no crescimento de micélio algodonoso esbranquiçado, revelando ao exame micromorfológico hifas raramente septadas com ramificações laterais frequentemente perpendiculares, sem estruturas reprodutivas e extremidades arredondadas, achados característicos de P. insidiosum.

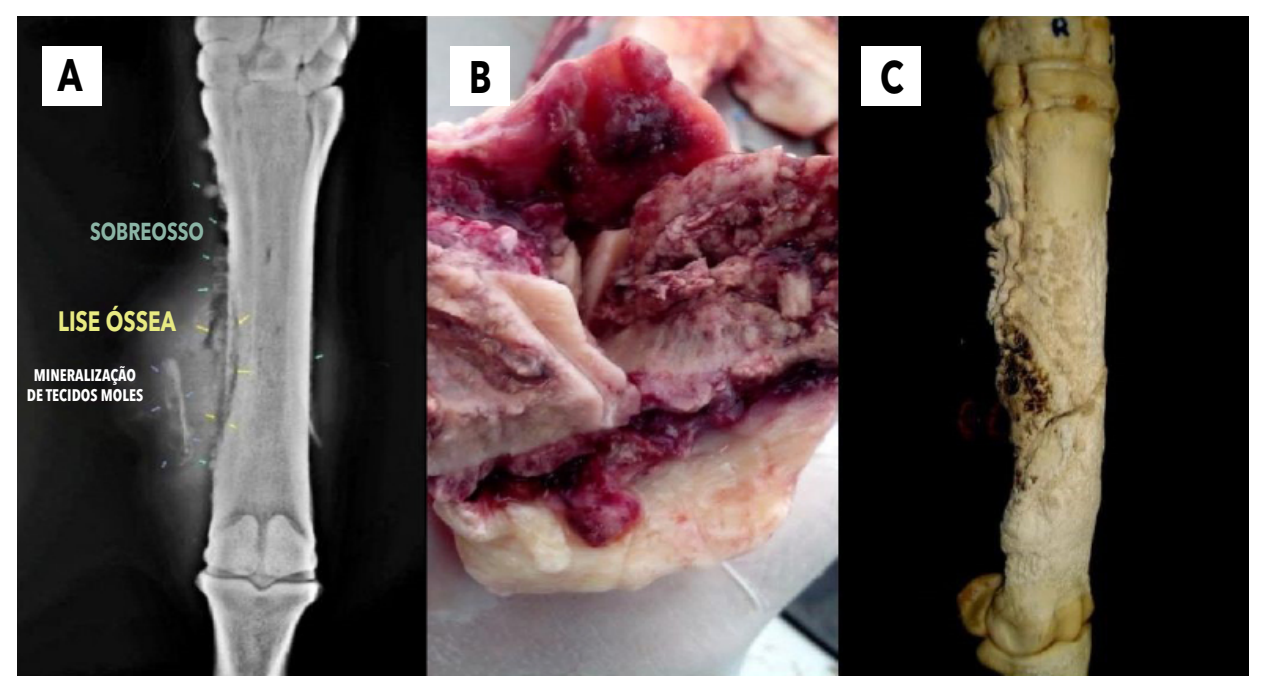

Figura 3 - (A) Projeção radiográfica dorso-palmar evidenciando alterações compatíveis com osteomielite e osteólise do $3^{\circ}$ e $4^{\circ}$ ossos metacárpicos esquerdos e mineralização dos tecidos moles em equino. (B) Imagem evidenciando fratura do osso $3^{\circ}$ metacarpo. (C) Vista médio dorsal da estrutura óssea dissecada com hiperostose no $3^{\circ}$ e $4^{\circ}$ metacarpos. 
Iniciou-se terapia para combate da osteomielite com ceftriaxona (40 $\mathrm{mgkg}^{-1}$ uma vez ao dia por 10 dias) acrescida da administração de iodeto de potássio via oral (67 $\mathrm{mgkg}^{-1}$ uma vez ao dia), no entanto, sete dias após a primeira administração, o animal apresentou fratura completa do MTE e foi submetido à eutanásia. Na necropsia não foram observadas lesões decorrentes de $P$. insidiosum nos órgãos internos, assim como em qualquer outra parte do corpo do animal, além do MTE. Neste, e também no interior da cicatriz cutânea, foram encontrados kunkers associados a lesões ósseas, tendões flexores escurecidos e fratura completa do terceiro metacarpo esquerdo. O osso na região acometida se apresentava friável, poroso e frágil à manipulação (Figura 3B). Histopatologicamente, verificouse a mesma reação inflamatória previamente identificada na biópsia óssea. Após maceração e digestão dos tecidos moles do MTE, as lesões ósseas observadas no exame radiográfico foram confirmadas. Adicionalmente, foi possível identificar acometimento da base da falange proximal (Figura 3C).

\section{Resultados e discussão}

Na região Norte Fluminense, a pitiose é a enfermidade mais comum que afeta a pele dos equinos, representando $47 \%$ das afecções cutâneas diagnosticadas nesta espécie no período de 2012 a 2014 (comunicação pessoal). As lesões acometem principalmente os membros locomotores ( $80 \%$ ) e abdômen (20\%) e consistem em feridas únicas, à semelhança do observado por outros autores (Leal etal., 2001; Marcolongo-Pereira et al., 2012). A evolução é rápida, acompanhada do aumento progressivo das lesões, emagrecimento, debilidade e mutilação, culminando muitas vezes com a morte dos animais (Carvalho et al., 2000). Possui relação direta com os períodos chuvosos e/ ou após estes (dezembro a março). A alta incidência da pitiose equina na região se deve provavelmente às características geográficas propícias ao desenvolvimento do agente, com campos planos e sujeitos a alagamentos frequentes e temperatura ambiental anual próxima aos $30{ }^{\circ} \mathrm{C}$. Além das características supramencionadas, o solo arenoso e as pastagens deficientes propiciam a presença constante de equinos dentro de lagos, várzeas e açudes à procura de alimentos que brotam nestes locais.

Técnicas de imuno-histoquímica, imunodifusão e, mais recentemente, as moleculares auxiliam e suportam o diagnóstico precoce e correto da pitiose (Santurio et al., 2006). No entanto a caracterização macroscópica das feridas granulomatosas com aspecto de pitiose em equinos, associada ao resultado histopatológico sugestivo para $P$. Insidiosum, constitui método de diagnóstico confiável (Dória et al., 2014). Os autores avaliaram 12 feridas granulomatosas em membros torácicos e pélvicos de equinos da raça Pantaneira e compararam o diagnóstico sugestivo para pitiose de acordo com as características clínicas das feridas, avaliação histopatológica (HE e Prata Metenamina de Grocott-Gomori) e imuno-histoquímica (método Streptavidina-biotina marcada). O diagnóstico foi de pitiose com 100\% de paridade entre os três métodos de avaliação. Neste relato, além do exame histopatológico e das características macroscópicas da lesão, com a presença de kunkers, o histórico de evolução da lesão, do local de criação, o prurido e a refratariedade aos tratamentos prévios realizados forneceram subsídios confiáveis que permitiram a suspeita clínica da doença. Adicionalmente, o exame radiográfico foi essencial para a verificação do comprometimento ósseo secundário (Dória et al., 2014).

Diversos protocolos de tratamento têm sido utilizados, com resultados variados: terapias exclusivamente clínicas, cirúrgicas ou a associação de ambas, que foi apontada por alguns autores como a mais indicada. A remoção cirúrgica, apesar de amplamente utilizada, não é pratica eficiente quando as lesões estão muito avançadas e/ou localizadas nos membros locomotores (Miller e Capbell, 1984), pois a impossibilidade de se excisar toda área acometida sem comprometer as estruturas anatômicas profundas diminui as chances de eliminação do agente, favorecendo a cronicidade da afecção (Mendoza et al.,1996) e predispondo o acometimento do tecido ósseo (Alfaro e Mendoza, 1990; Eaton, 1993). 
Ouso de iodeto de potássio sistêmico, associado ao sulfato de cobre tópico, resulta em cura parcial da lesão (Frey Jr. et al., 2007). Como alternativa de tratamento, a imunoterapia associada à cirurgia tem sido utilizada, mas apesar de apresentar eficácia comprovada de 50 a 83\%, há ocasiões em que as lesões não regridem totalmente (Meireles et al., 1993), como verificado no presente relato. Outra forma de tratamento descrita é a utilização de iodeto de potássio oral associado ao acetato de triancinolona administrado por via intramuscular, mostrando eficácia em $100 \%$ dos tratamentos sem comprometimento ósseo (Lemos et al., 2018). A explicação para o insucesso tratamento imunoterápico poderia se basear na existência de fatores individuais do animal tratado, como anergia ou ausência de estimulação (Sallis et al., 2003). Da mesma forma, o sucesso na terapia com o uso exclusivo de drogas antifúngicas tradicionais é difícil se for levado em conta que $P$. insidiosum não é um fungo e que o ergosterol, substância-alvo da maioria dos fármacos, está ausente na parede celular deste oomiceto (Monteiro, 1999).

Frente ao exposto, tem-se que o sucesso no tratamento, independentemente do método utilizado e/ou associado, depende do tempo de evolução das lesões, localização destas e capacidade de resposta imunológica do animal. Tem-se sugerido que alguns animais seriam mais resistentes e outros teriam uma maior prédisposição individual à infecção (MarcolongoPereira, 2012), o que poderia explicar o fato de $100 \%$ dos animais descritos na literatura (Alfaro e Mendoza, 1990; Eaton, 1993), e que apresentaram pitiose com envolvimento ósseo, terem sido submetidos à eutanásia ou terem morrido. No presente relato, a eutanásia foi indicada após ocorrência de fratura do membro acometido.

Através de estudo retrospectivo, não foram encontradas descrições de pitiose óssea equina no Brasil. Os relatos mais substanciais foram publicados pelo mesmo grupo de pesquisadores (Alfaro e Mendoza, 1990) e envolveram cinco animais da raça Crioula, machos e fêmeas, com 5 a 8 anos de idade. Para os autores, o número de cavalos com lesões ósseas pode ser maior do que o previamente divulgado, já que os membros locomotores são mais frequentemente afetados pelo $P$. insidiosum do que outras partes do corpo, aliado à ineficiência na remoção cirúrgica radical, fato já mencionado. O envolvimento ósseo ocorreu subsequente a lesões do sistema tegumentar, pois as lesões na pele levam ao desenvolvimento do fungo que, após se desenvolver, atinge o periósteo. Nestas condições, as lesões se caracterizam por exostoses, osteólises e osteomielites no exame radiológico, e massas necróticas contendo hifas no exame histopatológico (Grooters e Gee, 2002). No tecido ósseo (Eaton, 1993), através de estudo radiológico, observou-se irregularidade da superfície óssea com reações periosteais e severas erosões no carpo e metacarpos de um equino. Como no presente relato, também foram observadas áreas de necrose, descargas mucupurulentas e, na avaliação histopatológica, superfícies ulcerativas, tecido granulomatoso e hifas.

\section{Conclusão}

Feridas cutâneas de Pythium insidiosum, quando localizadas nos membros de equinos, podem desencadear lesões ósseas e devem, portanto, ser bem investigadas. O envolvimento do tecido ósseo e a incapacidade da exérese cirúrgica de toda a área lesionada pelo fungo constituem critérios para o estabelecimento de prognósticos desfavoráveis.

\section{Agradecimentos}

Os autores agradecem à Professora Helena K. Hokamura pelos ensinamentos e colaboração na realização dos exames radiográficos.

\section{Referências}

Alfaro AA, Mendoza L. Four cases of equine bone lesions caused by Pythium insidiosum. Equine Vet J. 1990;22(4):295-7.

Bosco SMG, Bagagli E, Araújo Jr JP, Candeias JMG, Franco MF, Marques MEA, et al. Human pythiosis, Brazil. Emerg Infect Dis. 2005;11(5):715-8. 
Carvalho ECQ, Lemos LS, Reis Jr JL. Pitiose equina: o popular formigueiro da Baixada Campista. Bol Tec UENF. 2000;1:1-48.

Dória RGS, Freitas SH, Mendonça FS, Arruda, LP, Boabaid FM, Martins-Filho A, et al. Utilização da técnica de imunohistoquímica para confirmar casos de pitiose cutânea equina diagnosticados por meio de caracterização clínica e avaliação histopatológica. Arq Bras Med Vet Zootec. 2014;66(1):27-33.

Eaton S. Osseous involvement by Pythium insidiosum. Comp Cont Educ Pract Veter. 1993;15(3):485-8.

Frey Jr F, Velho JR, Lins LA, Nogueira CEW, Santúrio JM. Pitiose equina na região sul do Brasil. Rev Port Cienc Vet. 2007;102(561-2):107-11.

Gaastra W, Lipman LJ, De Cock AW, Exel TK, Pegge RB, Scheurwater J, et al. Pythium insidiosum: an overview. Vet Microbiol. 2010;146(1-2):1-16.

Galiza GJN, Silva TM, Caprioli RA, Barros CSL, Irigoyen LF, Fighera RA, et al. Ocorrência de micoses e pitiose em animais domésticos: 230 casos. Pesq Vet Bras. 2014;34(3):224-32.

Grooters AM, Gee MK. Development of a nested polymerase chain reaction assay for the detection and identification of Pythium insidiosum. J Vet Intern Med. 2002; 16(2):147-52.

Leal ABM, Leal AT, Santurio JM, Kommers GD, Catto JB. Pitiose equina no pantanal brasileiro: Aspectos clínicopatológicos de casos típicos e atípicos. Pesq Vet Bras. $2001 ; 21(4): 151-6$.
Lemos GB, Petrucci LBDV, Vieira V, Di Filippo PA. Tratamento da pitiose cutânea equina com acetato de triancinolona e iodeto de potássio: relato de casos. Rev Acad Cienc Anim. 2018;16 (Ed Esp 2):e162507.

Marcolongo-Pereira C, Sallis ESV, Raffi MB, Pereira DIB, Hinnah FL, Coelho ACB, et al. Epidemiologia da pitiose equina na região sul do Rio Grande do Sul. Pesq Vet Bras. 2012;32(9):865-8.

Meireles MC, Riet-Correa F, Fischman O, Zambrano AF, Zambrano MS, Ribeiro GA. Cutaneous pythiosis in horses from Brazil. Mycoses. 1993;36(3-4):139-42.

Mendoza L, Ajello L, McGinnis MR. Infections caused by the Oomycetous pathogen Pythium insidiosum. J Mycol Med. 1996;6:151-64.

Miller RI, Campbell RSF. The comparative pathology of equine cutaneous phycomycosis. Vet Pathol. 1984;21(3):325-32.

Monteiro AB. Imunoterapia da pitiose equina: Teste de eficácia de um imunobiológico e avaliação leucocitária em animais infectados naturalmente pelo Pythium insidiosum [dissertação]. Santa Maria, RS: Universidade Federal de Santa Maria; 1999. 52 p.

Sallis ESV, Pereira DIB, Raffi MB. Pitiose cutânea em equinos: 14 casos. Cienc Rural. 2003;33(5):899-903.

Santurio JM, Alves SH, Pereira DB, Argenta JS. Pitiose: uma micose emergente. Acta Sci Vet. 2006;34(1):1-14. 